\title{
Objective and Self-Perceived Facial Skin Status Using Whitening Efficacy of Cosmetic Products on Taiwanese Women
}

\author{
Hsin-Tung Lin1, Gwo-Shing Chen², Feng-Lin Yen², Kuan-Nien Chen²* \\ ${ }^{1}$ Fiona International Limited, Taiwan \\ ${ }^{2}$ Kaohsiung Medical University, Taiwan \\ Email: yoyotw66616@gmail.com,d700086@kmu.edu.tw, ‘wc@kmu.edu.tw
}

Received 11 March 2016; accepted 27 June 2016; published 30 June 2016

Copyright (C) 2016 by authors and Scientific Research Publishing Inc.

This work is licensed under the Creative Commons Attribution International License (CC BY). http://creativecommons.org/licenses/by/4.0/

(c) (i) Open Access

\section{Abstract}

Background: Tranexamic acid and vitamin $C$ derivatives are important reagent used in cosmetic skin-whitening products. Recently, self-perceptions regarding improvement in facial skin status have been increasingly recognized as an important outcome of whitening cosmetic products intervention. Aims: The purpose of the study was to determine the receptiveness of objective and self-perceived facial skin status using whitening cosmetic products. Methods: A total of $\mathbf{4 0}$ volunteers were photographed using the Visia ${ }^{\circledR}$ machine and completed questionnaires at pre- and post-operation (8 weeks after receiving whitening cosmetic products). Visia ${ }^{\circledR}$ digital image analysis and questionnaires were used for assessment of facial skin status. The receptiveness of objective and self-perceived measures was assessed by paired $t$ test and Effect Size (ES). Results: There were progresses with regard to the surface spot $(E S=0.22)$, wrinkles $(E S=0.24)$, texture $(E S=0.31)$ and pores $(E S=0.21)$ after using cosmetic products with tranexamic acid. For self-perceived measures, there were significant progresses in pigmented spots $(E S=0.75)$, rough complexion $(E S=0.76)$, red complexion $(E S=0.41$ ), wrinkle $(E S=0.58)$ and obvious pores $(E S=0.75)$. Conclusions: This study suggests that the whitening cosmetic products are associated with improvement of objective and self-perceived facial skin status. The results could be provided as available information for cosmetic investigation.

\section{Keywords}

Whitening, Self-Perceived, Objective, Cosmetic, Facial Skin

\footnotetext{
${ }^{*}$ Corresponding author.
}

How to cite this paper: Lin, H.-T., Chen, G.-S., Yen, F.-L. and Chen, K.-N. (2016) Objective and Self-Perceived Facial Skin Status Using Whitening Efficacy of Cosmetic Products on Taiwanese Women. Journal of Cosmetics, Dermatological Sciences and Applications, 6, 117-123. http://dx.doi.org/10.4236/jcdsa.2016.64015 


\section{Introduction}

Several whitening agents such as hydroquinone, etinoic acid, tranexamic acid, vitamin $\mathrm{C}$ derivatives, 4-n-butylresorcinol, a-hydroxy acid and niacinamide have been used in cosmetic products but sometimes with side-effects [1]-[4]. Furthermore, tranexamic acid is effective on the skin in healing of wounds and has whitening effects [5]-[8]. Particularly, vitamin C derivatives such as sodium ascorbyl phosphate have been found antioxidant and anti-aging effects and can be used in many kinds of cosmetics. Examples for vitamin $\mathrm{C}$ derivatives and tranexamic acid in cosmetics products are skin-whitening lotions, creams, milky lotions, facial packs and scalp care cosmetics [9]. Sensitive detection and determination of tranexamic acid is thus of interest not only in cosmetics but also in clinical and pharmaceutical samples [10] [11].

Reviewing the literature, Visia ${ }^{\circledR}$ digital image analysis machine is commonly to evaluate objective assessments of facial skin status after several related clinical facial treatments [12]-[18]. In addition, participants' perceptions regarding improvements in facial skin status are increasingly recognized as an important outcome of cosmetic products intervention. There are limited studies observed both changes of objective and self-perceived assessments in whitening cosmetic products intervention.

The aim of this study was therefore to assess the receptiveness of the objective and self-perceived facial skin status using whitening cosmetic products by Taiwanese female adults.

\section{Materials and Methods}

\subsection{Study Design}

There are many methods to assess the efficiency of whitening or spot-removing materials [14]. Visia ${ }^{\circledR}$ digital image analysis machine is a common and validated clinical image machine used to evaluated objective assessments of facial skin in clinical facial treatments [12]-[18]. The study selected this machine to assess objective measures for facial skin status. The self-perceptions regarding improvements in facial skin status have been increasingly recognized as an important outcome for cosmetic products intervention. There is limited study observed changes of self-perceived assessments in cosmetic products. Our study developed five questions to assess the severity of self-perceived facial skin status contrast to aspects of objective facial skin status assessed by the Visia ${ }^{\circledR}$ machine. Additionally, the self-perceived questionnaire was assessed to be a reliable (Cronbach's alpha: 0.82 ) and valid measurement in this study.

This longitudinal study collected 40 volunteers aged 30 - 65 years working in the Kaohsiung Medical University or Kaoshiung Medical University Chung-Ho Memorial Hospital, presenting with pigmented spots, dyschromia or pigmentary disorders caused by solar exposure such as melasma and/or lentigo senilis, but not ephelides, nevus spilus or lentigo simplex, were recruited in the study. Persons on long-term treatment with anti-histamines, steroids or beta-blockers, and having a skin disease of the face, were excluded.

The use of cosmetic products except the exposure to sunlight (natural or artificial) in excess of habitual exposure was prohibited during the 8 weeks preceding and during the study period.

Participants accepted a bottle of whitening cosmetic product. They were photographed using the Visia ${ }^{\circledR}$ machine and completed questionnaires at pre- and post-operation (approximately 8 weeks after receiving cosmetic products). For safety reasons, if there was any uncomfortableness caused by the cosmetic product, the participant was allowed unconditionally to quit the job in the study.

This study was approved by the Institutional Review Board (Human Experiment and Ethics Committee, Kaohsiung Medical University Hospital, MUH-IRB-20130176).

\subsection{Ingredients of Whitening Products}

Contains active of the whitening serum is included tranexamic acid $2.5 \%$, Sodium ascorbyl phosphate $0.5 \%$, glutathione $0.005 \%$ and Hyaluronic acid $0.5 \%$. The serum $(60 \mathrm{ml})$ was pumped once to apply as regular serum every morning and evening during the study period ( 8 weeks).

\subsection{Clinical Evaluation}

On pre- and post-visits the face of the volunteer was photographed using a digital image analysis machine with polarized light $\left(\mathrm{Visia}^{\circledR}\right.$, Canfield Imaging System - Fairfield, EUA). Intent on capturing five skin properties 
(surface spot, red area, wrinkles, texture and pores), the objective of this study, we used the photographic image obtained with the ultraviolet lamp of the machine. Photographs were taken as proofs with the facing forward, $45^{\circ}$ to the right and $45^{\circ}$ to the left, combining all the facial regions analyzed for the presentation of results. The variables studied were count (number) of the five skin properties, as determined by the machine.

\subsection{Questionnaire Survey}

Five questions were developed to assess the severity of facial skin status contrast to aspects of objective facial skin status determined by the Visia ${ }^{\circledR}$ machine, and it is validated by cosmetic experts and dermatologists. Participants were asked how severely they had facial skin problems (pigmented spots, rough complexion, red complexion, wrinkle and obvious pores) at pre- and post-operation. Each question was calculated on 5-point severity scores $(1-5)$. More serious problem was indicated by higher scores.

\subsection{Statistical Analysis}

The statistical analysis of the study was conducted by using the software $\mathrm{SAS}^{\circledR} 9.2$ (SAS Institute Inc., Cary, NC, USA).

Internal consistency (reliability) was assessed for the self-perceived facial skin status questionnaire by Cronbach's alpha. The paired $t$ test was used to evaluate mean changes in objective and self-perceived outcome measures with respect to cosmetic products intervention. Cohen's standardized Effect Size (ES) [19], calculated by dividing the mean of the difference in pre- and post-operative scores by the standard deviation of the pre-treatment score, was computed to evaluate the receptiveness of different measurements. ES could be considered as several levels of clinical meaningfulness (small: $0.2 \leq \mathrm{ES}<0.5$; moderate: $0.5 \leq \mathrm{ES}<0.8$; large: $0.8 \leq \mathrm{ES}$ ).

\section{Result}

A total of 40 aged from 30 - 65 years were recruited. Each participant completed both pre- and post-questionnaires, and received cosmetic products with tranexamic acid $(60 \mathrm{ml})$.

For objective evaluation, receptiveness of facial skin status assessed on cosmetic products intervention was presented in Table 1. In general, there were significant differences between numbers of surface spot, wrinkles,

Table 1. Receptiveness of objective facial skin status using whitening cosmetic products for Taiwanese female $(n=40)$.

\begin{tabular}{|c|c|c|c|c|c|c|c|c|}
\hline & \multicolumn{2}{|c|}{ Baseline } & \multicolumn{2}{|c|}{ After 8 weeks } & \multicolumn{2}{|c|}{ Observed effect } & \multirow{2}{*}{ Paired t test $\mathrm{p}$-value } & \multirow{2}{*}{ Effect Size (ES) } \\
\hline & Mean & (SD) & Mean & (SD) & Mean & (SD) & & \\
\hline \multicolumn{9}{|l|}{ Total, $n=40$} \\
\hline Surface spot & 59.24 & $(14.67)$ & 55.97 & $(14.03)$ & 3.28 & $(6.09)$ & 0.0016 & 0.22 \\
\hline Wrinkles & 12.13 & (7.94) & 10.22 & $(6.75)$ & 1.92 & $(5.94)$ & 0.0479 & 0.24 \\
\hline Texture & 476.08 & $(255.08)$ & 397.43 & $(212.42)$ & 78.66 & $(132.81)$ & 0.0006 & 0.31 \\
\hline Pores & 241.93 & $(105.72)$ & 219.53 & $(92.52)$ & 22.41 & $(42.58)$ & 0.0019 & 0.21 \\
\hline Red Area & 116.28 & $(26.90)$ & 116.29 & $(33.71)$ & -0.02 & $(32.97)$ & 0.9975 & -0.00 \\
\hline \multicolumn{9}{|c|}{$30-50$ years, $n=25$} \\
\hline Surface spot & 55.85 & $(14.34)$ & 53.23 & $(14.61)$ & 2.63 & $(5.61)$ & 0.0278 & 0.18 \\
\hline Wrinkles & 8.15 & $(4.82)$ & 8.48 & $(6.27)$ & -0.33 & $(5.07)$ & 0.7452 & -0.07 \\
\hline Texture & 364.08 & $(165.23)$ & 346.01 & $(186.62)$ & 18.07 & $(69.82)$ & 0.2081 & 0.11 \\
\hline Pores & 211.04 & $(102.77)$ & 207.71 & $(97.81)$ & 3.33 & $(22.72)$ & 0.4704 & 0.03 \\
\hline Red Area & 111.68 & $(28.13)$ & 108.13 & $(24.82)$ & 3.55 & $(20.37)$ & 0.3927 & 0.13 \\
\hline \multicolumn{9}{|c|}{$50-65$ years, $n=15$} \\
\hline Surface spot & 64.89 & (13.88) & 60.53 & $(12.10)$ & 4.36 & $(6.89)$ & 0.0280 & 0.31 \\
\hline Wrinkles & 18.78 & $(7.74)$ & 13.11 & $(6.71)$ & 5.67 & $(5.47)$ & 0.0013 & 0.73 \\
\hline Texture & 662.76 & $(273.34)$ & 483.11 & $(231.09)$ & 179.64 & $(152.62)$ & 0.0004 & 0.66 \\
\hline Pores & 293.42 & $(92.13)$ & 239.22 & $(82.35)$ & 54.20 & $(49.32)$ & 0.0008 & 0.59 \\
\hline Red Area & 123.93 & $(23.64)$ & 129.89 & $(42.34)$ & -5.96 & $(47.49)$ & 0.6347 & -0.25 \\
\hline
\end{tabular}


texture, pores with regard to pre- and post-operation (paired t test p-values: 0.0016, 0.0479, 0.0006 and 0.0019 respectively). The mean change in numbers of surface spot, wrinkles and pores were 3.28, 1.92 and 22.41 from pre- operation to post-operation. Numbers of texture had the largest mean observed change (78.66). In addition, the effect size (ES) of the surface spot, wrinkles, texture and pores were $0.22,0.24,0.31$ and 0.21 , all effect size were above 0.20 showed at least a small improvement. Among 30 - 50 years participants $(n=25)$, there was only significant difference in numbers of surface spot with regard to pre- and post-operation (paired $t$ test $\mathrm{p}$-values: $0.0278)$. The ES of the surface spot was 0.18 . For $50-65$ years participants $(n=15)$, there were significant differences between numbers of surface spot, wrinkles, texture, pores with regard to pre- and post-operation (paired $\mathrm{t}$ test p-values: $0.0280,0.0013,0.0004$ and 0.0008 respectively). The ES of the surface spot, wrinkles, texture and pores were $0.31,0.73,0.66$ and 0.59 , all effect size were above 0.50 showed at least a moderate improvement except ES of surface spot.

The internal consistency analysis of the questionnaire resulted in a Cronbach's alpha of 0.82 . Alpha value decreased when any item was deleted. Considering item-total correlations, all items were above 0.50 (Table 2).

In terms of self-perceived assessment (Table 3), receptiveness of self-perceived facial skin status using whitening cosmetic products was showed in Table 3. In general, there were significant differences between pigmented spots, rough complexion, red complexion, wrinkle and obvious pores with regard to pre- and post-operation (paired

Table 2. Internal consistency reliability of self-perceived facial skin status questionnaire.

\begin{tabular}{ccc}
\hline Items & Item-total correlation & Alpha if item deleted \\
\hline Pigmented spots & 0.68 & 0.77 \\
Rough complexion & 0.71 & 0.77 \\
Red complexion & 0.51 & 0.82 \\
Wrinkle & 0.61 & 0.79 \\
Obvious pores & 0.60 & 0.79 \\
Cronbach's Alpha: 0.82 & & \\
\hline
\end{tabular}

Table 3. Receptiveness of self-perceived facial skin status using whitening cosmetic products for Taiwanese female $(\mathrm{n}=40)$.

\begin{tabular}{|c|c|c|c|c|c|c|c|c|}
\hline & \multicolumn{2}{|c|}{ Baseline } & \multicolumn{2}{|c|}{ After 8 weeks } & \multicolumn{2}{|c|}{ Observed effect } & \multirow{2}{*}{ Paired t test $\mathrm{p}$-value } & \multirow{2}{*}{ Effect Size (ES) } \\
\hline & Mean & (SD) & Mean & (SD) & Mean & (SD) & & \\
\hline \multicolumn{9}{|l|}{ Total, $n=40$} \\
\hline Pigmented spots & 3.45 & $(0.93)$ & 2.75 & $(0.54)$ & 0.70 & $(0.82)$ & $<0.0001$ & 0.75 \\
\hline Rough complexion & 3.20 & $(0.85)$ & 2.55 & $(0.64)$ & 0.65 & $(0.86)$ & $<0.0001$ & 0.76 \\
\hline Red complexion & 2.70 & (1.14) & 2.23 & $(0.83)$ & 0.48 & $(1.22)$ & 0.0183 & 0.41 \\
\hline Wrinkle & 3.15 & $(0.95)$ & 2.60 & $(0.63)$ & 0.55 & $(0.81)$ & 0.0001 & 0.58 \\
\hline Obvious pores & 3.48 & $(1.04)$ & 2.70 & $(0.56)$ & 0.78 & $(1.12)$ & $<0.0001$ & 0.75 \\
\hline \multicolumn{9}{|l|}{$30-50$ years, $n=25$} \\
\hline Pigmented spots & 3.60 & $(0.91)$ & 2.80 & $(0.50)$ & 0.80 & $(0.82)$ & $<0.0001$ & 0.88 \\
\hline Rough complexion & 3.28 & $(0.74)$ & 2.68 & $(0.63)$ & 0.60 & $(0.76)$ & 0.0006 & 0.81 \\
\hline Red complexion & 2.92 & $(1.12)$ & 2.40 & $(0.82)$ & 0.52 & $(1.08)$ & 0.0247 & 0.46 \\
\hline Wrinkle & 3.24 & $(1.05)$ & 2.68 & $(0.56)$ & 0.56 & $(0.87)$ & 0.0037 & 0.53 \\
\hline Obvious pores & 3.64 & $(0.91)$ & 2.80 & $(0.50)$ & 0.84 & $(0.90)$ & $<0.0001$ & 0.92 \\
\hline \multicolumn{9}{|l|}{$50-65$ years, $n=15$} \\
\hline Pigmented spots & 3.20 & $(0.94)$ & 2.67 & $(0.62)$ & 0.53 & $(0.83)$ & 0.0266 & 0.56 \\
\hline Rough complexion & 3.07 & $(1.03)$ & 2.33 & $(0.62)$ & 0.73 & $(1.03)$ & 0.0156 & 0.72 \\
\hline Red complexion & 2.33 & $(1.11)$ & 1.93 & $(0.80)$ & 0.40 & $(1.45)$ & 0.3047 & 0.36 \\
\hline Wrinkle & 3.00 & $(0.76)$ & 2.47 & $(0.74)$ & 0.53 & $(0.74)$ & 0.0148 & 0.70 \\
\hline Obvious pores & 3.20 & $(1.21)$ & 2.53 & $(0.64)$ & 0.67 & $(1.45)$ & 0.0961 & 0.55 \\
\hline
\end{tabular}


t test p-values: $<0.0001,<0.0001,0.0183,0.0001$ and $<0.0001$ respectively). The mean change in pigmented spots, rough complexion, red complexion, wrinkle and obvious pores were $0.70,0.65,0.48,0.55$ and 0.78 from pre- operation to post- operation. Moreover, the ES of the pigmented spots, rough complexion, red complexion, wrinkle and obvious pores were $0.75,0.76,0.41,0.58$ and 0.75 , all effect size were above 0.50 showed at least a moderate improvement except ES of red complexion. Among 30 - 50 years participants, there were significant differences between pigmented spots, rough complexion, red complexion, wrinkle and obvious pores with regard to pre- and post-operation (paired t test p-values: $<0.0001,0.0006,0.0247,0.0037$ and $<0.0001$ respectively). The ES of the pigmented spots, rough complexion, red complexion, wrinkle and obvious pores were 0.88 , $0.81,0.46,0.53$ and 0.92 . Particularly, the ES of pigmented spots, rough complexion and obvious pores were above 0.80 showed at least a large improvement. For 50 - 65 years participants $(n=15)$, there also were significant differences between pigmented spots, rough complexion and wrinkle with regard to pre- and post-operation (paired t test p-values: $0.0266,0.0156$ and 0.0148 respectively). The ES of the pigmented spots, rough complexion and wrinkle were $0.56,0.72$ and 0.70 , and they were above 0.50 showed at least a moderate improvement except ES of surface spot.

\section{Discussion}

Limited studies have followed longitudinally the receptiveness of objective and self-perceived facial skin status using cosmetic products. In the present study, there were improvements not only in surface spot, wrinkles, texture and pores facial skin status, but also in self-perceived pigmented spots, rough complexion, red complexion, wrinkle and obvious pores facial skin problems after using whitening cosmetic products.

It has recently been proposed that tranexamic acid is not only a synthetic antifibrinolytic agent but also a whitening ingredient in cosmetics [10] [20]. In addition, antioxidants are becoming increasingly important in whitening cosmetics according to their anti-inflammatory effects. Particularly, 3\% sodium ascorbyl phosphate is a stable antioxidants in a cosmetic oil-in-water emulsion and enable a good release of the active agent in vitro as a precondition for a high efficacy in vivo [21] [22]. In present study, the whitening efficacy products contains both tranexamic acid and sodium ascorbyl phosphate active ingredients were provided participants, and then observing the changes in self-perceived and objective facial skin status.

There is recent information regarding the investigation into the effect of vitamin $\mathrm{C}$ derivatives and tranexamic acid in cosmetic products [3]. In this study, the surface spot, wrinkles, texture and pores were significant improvements after using whitening cosmetic products. However, red facial skin wasn't proven improved. Compared with younger participants (30 - 50 years), older participants ( $>50$ years) had lager changes in aspects of wrinkles, texture and pores because their facial skin were worse at baseline. For self- perception, participants also felt that aspects of pigmented spots, rough complexion, red complexion, wrinkle and obvious pores problems were improved, in, particular, the improvements in pigmented spots, rough complexion, and obvious pores problems were larger. Compared with older participants (>50 years), younger participants (30 - 50 years) had more self-perceived improved aspects of facial skin status such as red skin and obvious pores problems. Maybe younger females pay more attention to their appearance, and further they feel more changes in their facial skin. The results of our study could be provided as available information for cosmetic investigations.

This study had a limitation. There was no control group in this follow-up study, and hence the receptiveness cannot be considered as effectiveness for whitening cosmetic products in objective and self-perceived facial skin status. Therefore, future research may be required to explore effectiveness of whitening cosmetic products in self-perceived outcomes.

\section{Conclusion}

It was found in the study that whitening cosmetic products could improve surface spots, wrinkles, texture and pores facial skin status. In terms of participants' self-perceived facial skin status, there were also significant improvements in aspects of pigmented spots, rough complexion, red complexion, wrinkle and obvious pores. People at different age levels could feel about how the products help their facial skin in different ways. These results are relevant for cosmetic experts and dermatologists who wish to draw on scientific evidence about the benefits of cosmetic products when advising consumers about whether or not the products will improve their facial skin status. 


\section{Acknowledgements}

All authors have made substantive contribution to this study, and all have reviewed the final paper prior to its submission.

\section{References}

[1] Haddad, A.L., Matos, L.F., Brunstein, F., et al. (2003) A Clinical, Prospective, Randomized, Double-Blind Trial Comparing Skin Whitening Complex with Hydroquinone vs. Placebo in the Treatment of Melasma. International Journal of Dermatology, 42, 153-156. http://dx.doi.org/10.1046/j.1365-4362.2003.01621.x

[2] Griffiths, C.E., Finkel, L.J., Ditre, C.M., et al. (1993) Topical Tretinoin (Retinoic Acid) Improves Melasma. A Vehicle-Controlled, Clinical Trial. British Journal of Dermatology, 129, 415-421. http://dx.doi.org/10.1111/j.1365-2133.1993.tb03169.x

[3] Tadokoro, T., Bonte, F., Archambault, J.C., et al. (2010) Whitening Efficacy of Plant Extracts Including Orchid Extracts on Japanese Female Skin with Melasma and Lentigo Senilis. The Journal of Dermatology, 37, 522-530. http://dx.doi.org/10.1111/j.1346-8138.2010.00897.x

[4] Son, K.H. and Heo, M.Y. (2013) The Evaluation of Depigmenting Efficacy in the Skin for the Development of New Whitening Agents in Korea. International Journal of Cosmetic Science, 35, 9-18. http://dx.doi.org/10.1111/ics.12012

[5] McCormack, P.L. (2012) Tranexamic Acid: A Review of Its Use in the Treatment of Hyperfibrinolysis. Drugs, 72, 585-617. http://dx.doi.org/10.2165/11209070-000000000-00000

[6] Shih, Y., Wu, K.L., Sue, J.W., et al. (2008) Determination of Tranexamic Acid in Cosmetic Products by High-Performance Liquid Chromatography Coupled with Barrel Plating Nickel Electrode. Journal of Pharmaceutical and Biomedical Analysis, 48, 1446-1450. http://dx.doi.org/10.1016/j.jpba.2008.09.019

[7] Manosroi, A., Podjanasoonthon, K. and Manosroi, J. (2002) Stability and Release of Topical Tranexamic Acid Liposome Formulations. Journal of Cosmetic Science, 53, 375-386.

[8] Duangrat, C., Wongsri, K. and Pongpaibul, Y. (2007) Spectrofluorimetric Determination of Tranexamic Acid in Hydrogel Patch Formulations by Derivatization with Naphthalene-2,3-Dicarboxaldehyde/Cyanide. Journal of Cosmetic Science, 58, 215-227.

[9] Tse, T.W. and Hui, E. (2013) Tranexamic Acid: An Important Adjuvant in the Treatment of Melasma. Journal of Cosmetic Dermatology, 12, 57-66. http://dx.doi.org/10.1111/jocd.12026

[10] Budamakuntla, L., Loganathan, E., Suresh, D.H., et al. (2013) A Randomised, Open-label, Comparative Study of Tranexamic Acid Microinjections and Tranexamic Acid with Microneedling in Patients with Melasma. Journal of Cutaneous and Aesthetic Surgery, 6, 139-143. http://dx.doi.org/10.4103/0974-2077.118403

[11] Cho, H.H., Choi, M., Cho, S., et al. (2013) Role of Oral Tranexamic Acid in Melasma Patients Treated with IPL and Low Fluence QS Nd: YAG Laser. The Journal of Dermatological Treatment, 24, 292-296. http://dx.doi.org/10.3109/09546634.2011.643220

[12] Kulick, M.I. and Gajjar, N.A. (2007) Analysis of Histologic and Clinical Changes Associated with Polaris WR Treatment of Facial Wrinkles. Aesthetic Surgery Journal, 27, 32-46. http://dx.doi.org/10.1016/j.asj.2006.12.011

[13] Costa, A., Moises, T.A., Cordero, T., et al. (2010) Association of Emblica, Licorice and Belides as an Alternative to Hydroquinone in the Clinical Treatment of Melasma. Anais Brasileiros de Dermatologia, 85, 613-620. http://dx.doi.org/10.1590/S0365-05962010000500003

[14] Puccetti, G., Nguyen, T. and Stroever, C. (2011) Skin Colorimetric Parameters Involved in Skin Age Perception. Skin Research and Technology, 17, 129-134. http://dx.doi.org/10.1111/j.1600-0846.2010.00480.x

[15] Chan, N.P., Shek, S.Y., Yu, C.S., et al. (2011) Safety Study of Transcutaneous Focused Ultrasound for Non-Invasive Skin Tightening in Asians. Lasers in Surgery and Medicine, 43, 366-375. http://dx.doi.org/10.1002/1sm.21070

[16] Herane, M.I., Orlandi, C., Zegpi, E., et al. (2012) Clinical Efficacy of Adapalene (Differin((R))) $0.3 \%$ gel in Chilean Women with Cutaneous Photoaging. Journal of Dermatological Treatment, 23, 57-64. http://dx.doi.org/10.3109/09546634.2011.631981

[17] Michaels, B.M., Csank, G.A., Ryb, G.E., et al. (2012) Prospective Randomized Comparison of OnabotulinumtoxinA (Botox) and AbobotulinumtoxinA (Dysport) in the Treatment of Forehead, Glabellar, and Periorbital Wrinkles. Aesthetic Surgery Journal, 32, 96-102. http://dx.doi.org/10.1177/1090820X11430685

[18] Arjinpathana, N. and Asawanonda, P. (2012) Glutathione as an Oral Whitening Agent: A Randomized, Double-Blind, Placebo-Controlled Study. Journal of Dermatological Treatment, 23, 97-102. http://dx.doi.org/10.3109/09546631003801619

[19] Cohen, J. (1992) A Power Primer. Psychological Bulletin, 112, 155-159. 
http://dx.doi.org/10.1037/0033-2909.112.1.155

[20] Huertas-Perez, J.F., Heger, M., Dekker, H., et al. (2007) Simple, Rapid, and Sensitive Liquid Chromatography-Fluorescence Method for the Quantification of Tranexamic Acid in Blood. Journal of Chromatography A, 1157, $142-150$. http://dx.doi.org/10.1016/j.chroma.2007.04.067

[21] Raschke, T., Koop, U., Dusing, H.J., et al. (2004) Topical Activity of Ascorbic Acid: From in Vitro Optimization to in Vivo Efficacy. Skin Pharmacology and Physiology, 17, 200-206. http://dx.doi.org/10.1159/000078824

[22] Tian, Y., Hoshino, T., Chen, C.J., et al. (2009) The Evaluation of Whitening Efficacy of Cosmetic Products Using a Human Skin Pigmentation Spot Model. Skin Research and Technology, 15, 218-223. http://dx.doi.org/10.1111/j.1600-0846.2009.00358.x

\section{Submit or recommend next manuscript to SCIRP and we will provide best service for you:}

Accepting pre-submission inquiries through Email, Facebook, Linkedin, Twitter, etc A wide selection of journals (inclusive of 9 subjects, more than 200 journals)

Providing a 24-hour high-quality service

User-friendly online submission system

Fair and swift peer-review system

Efficient typesetting and proofreading procedure

Display of the result of downloads and visits, as well as the number of cited articles

Maximum dissemination of your research work

Submit your manuscript at: http://papersubmission.scirp.org/ 